\title{
Proline transport inhibitors trigger differential responses in Trypanosoma cruzi growth inhibition
}

María Sol Ballari, ${ }^{1, \ddagger}$ Lucia Fargnoli, ${ }^{1, \neq}$ Lucas Pagura, ${ }^{2}$ Julia A. Cricco, ${ }^{2}$ Ariel M. Silber ${ }^{3}$ and Guillermo R. Labadie ${ }^{1,4 *}$

${ }^{1}$ Instituto de Química de Rosario (IQUIR), Facultad de Ciencias Bioquímicas y Farmacéuticas. Universidad Nacional de Rosario. Rosario, Argentina.

${ }^{2}$ Instituto de Biología Molecular y Celular de Rosario (IBR), Consejo Nacional de Investigaciones Científicas y Técnicas CONICET - Facultad de Ciencias Bioquímicas y Farmacéuticas, Universidad Nacional de Rosario, Rosario, Argentina.

${ }^{3}$ Laboratory of Biochemistry of Tryps - LaBTryps, Departamento de Parasitologia, Instituto de Ciências Biomédicas, Universidade de São Paulo, Cidade Universitária, São Paulo, Brazil.

${ }^{4}$ Departamento de Química Orgánica, Facultad de Ciencias Bioquímicas y Farmacéuticas, Universidad Nacional de Rosario, Rosario, Argentina

*Corresponding author: labadie@iquir-conicet.gov.ar

${ }^{\ddagger}$ Both authors contributed equally to this work

Tel.: +54-341-4370477 \# 108

Fax: +54-341-4370477 \# 112 


\section{Abstract}

Background: Proline is a fundamental amino acid for Trypanosoma cruzi, the etiological agent of Chagas disease. Proline is mainly incorporated from the extracellular medium by amino acid transport systems. Different proline analogues proved to interact with the proline permease TcAAAP069 and inhibit the proline uptake by T. cruzi.

Methods: Decyl- (1), oleyl- (2) and farnesyl- (3) substituted proline analogues were evaluated on six T. cruzi DTUs. Cell death type was determined by flow cytometry, and the effect on the parasite metabolism was analysed by directed NMR exometabolomics. Structural modifications of 1 (compounds $4-6$ ) were implemented to have more information on the mode of action (MoA).

Results: The compounds showed broad-spectrum activity against all DTUs. Compound $\mathbf{3}$ at high concentration $(116 \mu \mathrm{M})$ induced necrosis. The removal of the triazole from 1 proved to be important for the activity. Compounds $\mathbf{1}$ and $\mathbf{2}$ induced deep changes in the exometabolome, diminishing the amounts of succinate, lactate, acetate, and ethanol excreted. The fluorescent labelling and subsequent microscopy showed that compound $\mathbf{1}$ can be taken up by epimastigotes.

Conclusions: Two different MoA related to proline transport for decyl and farnesyl-substituted proline analogues are proposed. The former presented an in-cell action while the latter was not taken up by the parasites but interacted with the extracellular side of the proline permease.

General Significance: Subtle structural variations in the compounds determine differences in the MoA. This finding opens new perspectives that should be examined on the development of new drugs targeting metabolite permeases.

Keywords: Trypanosoma cruzi, proline transport, NBD, fluorescence microscopy, cell death, directed metabolomics. 


\section{Introduction}

Chagas disease, which etiological agent is Trypanosoma cruzi, is a parasitic disease classified within the group of neglected tropical diseases (NTDs), and constitutes a public health problem in the Americas. The genetic, biochemical and biological diversity of $T$. cruzi strains has long been recognized through both ecological and epidemiological complexity ${ }^{1-3}$. Over the years, many attempts were made to characterize the $T$. cruzi population structure, in order to define a relevant number of subgroups. Taking this into account, T. cruzi strains were classified in six discrete typing units (DTUs, Tcl - VI) ${ }^{1,4}$. DTUs have differences in infectivity of different vector species, host cells, virulence, their ability to induce injury, tropism and antigenic constitution. Furthermore, they have morphological differences in blood forms, growth rate, and susceptibility to chemotherapeutic agents ${ }^{5,6}$.

Throughout its life cycle, T. cruzi can withstand different extracellular conditions in the insect's intestine, the mammalian bloodstream and the different host-cells cytoplasm. Each one of these environments 'offers' to the parasite a different set of metabolites for establishing the infection, proliferation and survival. In this sense, the parasite developed evolutionary adaptations, which include its ability to rapidly switch from a metabolism based on the consumption of carbohydrates, to a metabolism based on the consumption of amino acids ${ }^{7,8}$. Among them, it has been early recognized the relevance of proline metabolism ${ }^{9}$.

Proline had shown to be a multi-functional metabolite in T. cruzi. It was well demonstrated its role in cell differentiation in the insect vector ${ }^{10,11}$ and in the infected mammalian cell ${ }^{12}$. In addition, it is involved in the amastigote survival ${ }^{13}$, the resistance to oxidative stress ${ }^{14-16}$, in the ATP production ${ }^{15,17,18}$ and it was proposed its participation in a redox shuttle able to rebalance the redox power between the cytosol and the cell single mitochondrion ${ }^{19}$. In order to be available inside the cell, proline can be taken up from the extracellular medium by two active transporters ${ }^{16,20}$ or, alternatively, can be biosynthesized from glutamate ${ }^{19}$. Once inside the cell, it has two possible metabolic fates beyond the obvious one as a constituent of proteins: it can be stored at 
millimolar concentrations inside the cell ${ }^{12}$, where it can be racemized to produce D-Proline by a proline racemase ${ }^{21}$, or it can be oxidized in the mitochondria by two enzymes acting sequentially, a proline dehydrogenase and a P5C dehydrogenase, producing $\mathrm{FADH}_{2}$ and $\mathrm{NADH}$, respectively $15,18$.

Despite the fact that its biosynthesis from glutamate has been demonstrated as well, there are strong evidences that proline transport activity is critical for the parasite survival and proliferation. In a previous work, we have been able to prepare L-proline derivatives as possible inhibitors of the incorporation of this amino acid in T. cruzi. The resulting synthetic library allowed us to find four analogues with $\mathrm{IC}_{50}$ values in CL14 strain T. cruzi epimastigotes under $50 \mu \mathrm{M}^{22}$, much lower than L-thiazolidine-4- carboxylic acid $\left(T 4 C, I_{50}=890 \mu M\right)$, the only reported precedent in $T$. cruzi ${ }^{14}$. Additionally, it was possible to determine that two of these compounds with anti-proliferative activity (1 and $\mathbf{3}$, Fig. $\mathbf{1}$ ) were capable of inhibiting the proline transporter TcAAAP069 ${ }^{23}$, belonging to the first multigenic family of amino acid transporters identified in $T$. cruzi, the TcAAAP family (Trypanosoma cruzi Amino Acid/Auxin Permeases) ${ }^{24}$. From these assays, it was remarkable that both compounds exhibited different kinds of transport inhibition.

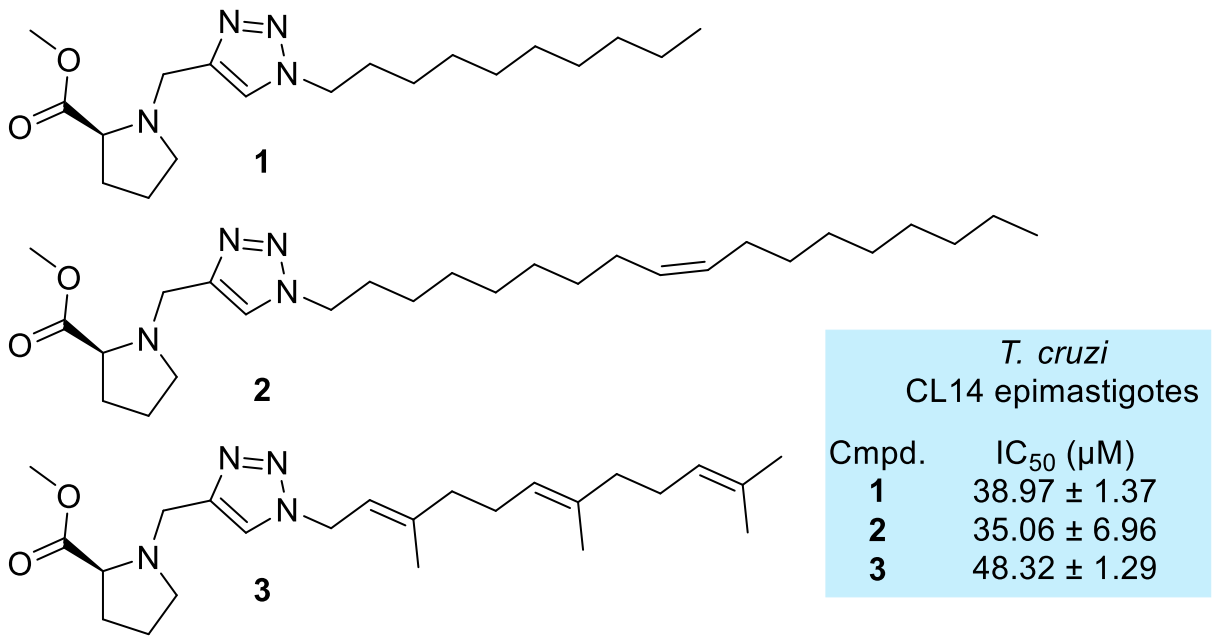

Fig. 1. L-proline analogues under study

Knowing that proline derivatives $\mathbf{1}$ and $\mathbf{3}$ have different effects on the proline transport system, we used them as tools to get a better understanding of the role of the proline transport on the trypanocidal/trypanostatic activity. In the present work, we analyse three of these compounds (1, 2 and 3, Fig. 1) in terms of their range of activity against strains belonging to the six different $T$. cruzi DTUs. We approach as well the mode of action of analogue 1 , through the use of a 
fluorescent chemical probe and non-triazolic analogues. Additionally, we determined the cell death mechanism triggered by each compound. Finally, we characterized the metabolic alterations induced by the proline analogues through NMR targeted exometabolomics.

\section{Materials and Methods}

\subsection{Microorganisms and growth conditions of Trypanosoma cruzi}

T. cruzi strains employed: Sylvio (DTU Tcl), Y (DTU Tcll), M6241 (DTU TcllI), Can III (DTU TclV), 92:80 (DTU TcV), CL14 (DTU TcVI), Dm28c (DTU Tcl).

Epimastigotes of $T$. cruzi were maintained in the exponential phase of growth by successive passages at $28{ }^{\circ} \mathrm{C}$ (every 48 hours) in LIT medium (Liver Infusion Tryptose), containing liver infusion $5 \mathrm{~g} / \mathrm{L}$, tryptose $5 \mathrm{~g} / \mathrm{L}, \mathrm{NaCl} 4 \mathrm{~g} / \mathrm{L}, \mathrm{KCl} 0.4 \mathrm{~g} / \mathrm{L}, \mathrm{Na}_{2} \mathrm{HPO}_{4} 8 \mathrm{~g} / \mathrm{L}$, hemin $10 \mathrm{~g} / \mathrm{L}$, supplemented with $10 \%$ fetal bovine serum and glucose at a final concentration of $0.2 \%, \mathrm{pH} 7.2^{25}$, except otherwise specified.

\subsection{Proliferation of $T$. cruzi}

The epimastigotes proliferation curves were performed in LIT medium. The curves were initiated with $1 \times 10^{7}$ parasites $/ \mathrm{mL}, 2 \times 10^{7}$ parasites $/ \mathrm{mL}, 3 \times 10^{7}$ parasites $/ \mathrm{mL}$ or $4 \times 10^{7}$ parasites $/ \mathrm{mL}$. The parasites were cultured in 96-well culture plates, and the proliferation was followed up by counting the number of cells in a Neubauer chamber. Alternatively, the proliferation was followed spectrophotometrically, up by measuring the optical density at a wavelength of $620 \mathrm{~nm}$ and comparing the data with those from a calibration curve, as described by Magdaleno et $\mathrm{al}^{14}$.

\section{3. $I_{50}$ determination in $T$. cruzi epimastigotes}

Exponentially proliferating $T$. cruzi epimastigotes $\left(5 \times 10^{6}\right.$ cells $\left./ \mathrm{mL}\right)$ were seeded in 96 -well plates and further treated with different concentrations of each analogue (concentration range from 25 to $250 \mu \mathrm{M})$ or untreated (negative control). As a positive control, a combination of rotenone $(60 \mu \mathrm{M})$ and antimycin $(0.5 \mu \mathrm{M})$ was used. The plates were incubated at $28^{\circ} \mathrm{C}$ for 7 days. Cell proliferation was spectrophotometrically measured by recording the absorbance at $620 \mathrm{~nm}$ every $24 \mathrm{~h}$ for 7 days. The absorbance was transformed into cell density values (cells $/ \mathrm{mL}$ ) using a linear regression 
equation that was previously obtained under the same conditions. Data from the mid-exponential growth phase (4th day) were used to determine the concentration of the analogues that inhibited $50 \%$ of the parasite proliferation $\left(\mathrm{IC}_{50}\right)$. For this, we explored classic dose-response sigmoid functions to find the best fit to the obtained data ${ }^{14}$. Each experiment was made in triplicates, and the results presented correspond to the average of three independent experiments.

\subsection{Confocal microscopy}

T. cruzi, strain Dm28c epimastigotes were incubated with $25 \mu \mathrm{M}$ of compound 4 for 30 minutes at room temperature. Then, the cells were fixed with $500 \mu \mathrm{L}$ of $3.7 \%$ formaldehyde $(w / v)$ in PBS, washed twice with PBS, suspended in $40 \mu \mathrm{L}$ of PBS, settled on polylysine-coated coverslips and mounted with VectaShield. All the images were acquired with a confocal Zeiss LSM880 microscope using Zeiss Zen software. The emission of the samples displaying green fluorescence (treated with 6) was registered at 490/535 nm under Argon laser excitation (488 nm). The emission of the samples treated with DAPI was registered at $430 / 50 \mathrm{~nm}$ under laser excitation $(405 \mathrm{~nm})^{26}$. All the images were processed using the ImageJ software ${ }^{27}$.

\subsection{Cell death mechanism}

T. cruzi, strain CL14 epimastigotes $\left(5 \times 10^{6}\right.$ cells $\left./ \mathrm{mL}\right)$ were cultured in LIT medium at $28{ }^{\circ} \mathrm{C}$ and treated with compounds $\mathbf{1}, \mathbf{2}$ and $\mathbf{3}$ at their respective $\mathrm{IC}_{50}$ or $\mathrm{IC}_{80}$ concentration. On the third day of incubation, treated cells and controls $\left(1 \times 10^{6}\right.$ cells $\left./ \mathrm{mL}\right)$ were washed once with annexin buffer (10 mM HEPES, $140 \mathrm{mM} \mathrm{NaCl}$ and $2.5 \mathrm{mM} \mathrm{CaCl}, \mathrm{pH}$ 7.4) and resuspended in $50 \mu \mathrm{L}$ of the same buffer. The parasites were incubated in ice (protected from light), for 15 minutes, in the presence of annexin-V FITC (Invitrogen, Eugene, Oregon, USA), according to the manufacturer's instructions, and $1 \mu \mathrm{g} / \mathrm{mL}$ propidium iodide. Then, $450 \mu \mathrm{L}$ of annexin buffer was added, and the parasites were analysed by flow cytometry ${ }^{28}$. The parasites were examined using a FACSCalibur cytometer (BD Biosciences), with 10,000 events collected and analysed using Flowing Software 2.

\subsection{Determination of metabolic change}

Parasites $\left(0.5 \times 10^{6}\right.$ epimastigotes $/ \mathrm{mL}$ of strain Dm28c) grown in LIT medium were transferred to DMEM (high glucose concentration) $2 \%$ SFB culture medium, and incubated at $27^{\circ} \mathrm{C}$, for $48 \mathrm{~h}$ for 
adaptation. Then, the parasites were washed trice by centrifugation (3500 $\times g, 5$ minutes at room temperature) and resuspended in DMEM 2\% SFB. After the last step, parasites resuspended in DMEM $2 \%$ SFB were seeded in 6-well plates (4 mL per well) in the presence of each compound at a final concentration equivalent to its $\mathrm{IC}_{50}$, and incubated for $96 \mathrm{~h}$ at $27^{\circ} \mathrm{C}$. As controls, parasites were incubated in DMEM $2 \%$ SFB without any addition, or supplemented with $0.02 \%$ DMSO, the diluent of the compounds at the maximum concentration it was added for the treatments. Parasites were separated by centrifugation at $7500 \times g$ for 10 minutes. The supernatants were collected and filtered through $0.2 \mu \mathrm{m}$ filters. The filtrates were then prepared for NMR spectroscopy. Samples (400 $\mu \mathrm{L}$ of filtered medium) were added with $10 \mu \mathrm{L}$ DMSO- $d^{6}$ (internal standard) and $90 \mu \mathrm{L}$ of $\mathrm{D}_{2} \mathrm{O}$. Strandards for each metabolite were prepared by mixing $398 \mu \mathrm{L}$ of distilled $\mathrm{H}_{2} \mathrm{O}, 2 \mu \mathrm{L} 1 \mathrm{M}$ concentration of each metabolite, $90 \mu \mathrm{L} \mathrm{D}{ }_{2} \mathrm{O}$ and $10 \mu \mathrm{L}$ DMSO- $d^{6}$ (internal standard). Progressive additions ( $2 \mu \mathrm{L}$ each) of $1 \mathrm{M}$ stocks of metabolite were made until metabolite NMR signal was detected. The 1D NOESY-pr spectra were acquired on a Bruker Advance II $300 \mathrm{MHz}$, making a total of 48 accumulations. The results were expressed as a percentage relative to DMSO and with respect to the control of the analysed strain.

\section{Results}

\subsection{Proline analogues are active against all T. cruzi DTUs (Tc I - VI)}

According to DNDi, an acceptable Target Product Profile needs to inhibit the proliferation of T. cruzi DTUs I, II, V and VI, but ideally a drug should inhibit the proliferation of all them ${ }^{29}$. Taking this into account, we set out to determine if the antiparasitic activity of our compounds against representative strains of each one of the six DTUs.

As was mentioned, based on previous work ${ }^{22,23}$, proline analogues $\mathbf{1}$ - $\mathbf{3}$ (Fig. 1) were selected for this study. Analogue $\mathbf{2}$ was included in the study as a control, since it did not present a proline transport-dependant mode of action. Compounds 1 - $\mathbf{3}$ were assayed against epimastigotes of strains belonging to DTUs Tcl to TcVI. The effect those compounds asserted in each DTU was followed for 6 to 11 days, and $\mathrm{IC}_{50}$ S were determined at the time when parasites were in the midexponential growth phase. Growth and drug-response curves obtained for analogue 1 in the 
different DTUs are represented in Fig. 2. The same curves obtained for analogues $\mathbf{2}$ and $\mathbf{3}$ can be found in the Supporting Information, Figures S1 and S2.
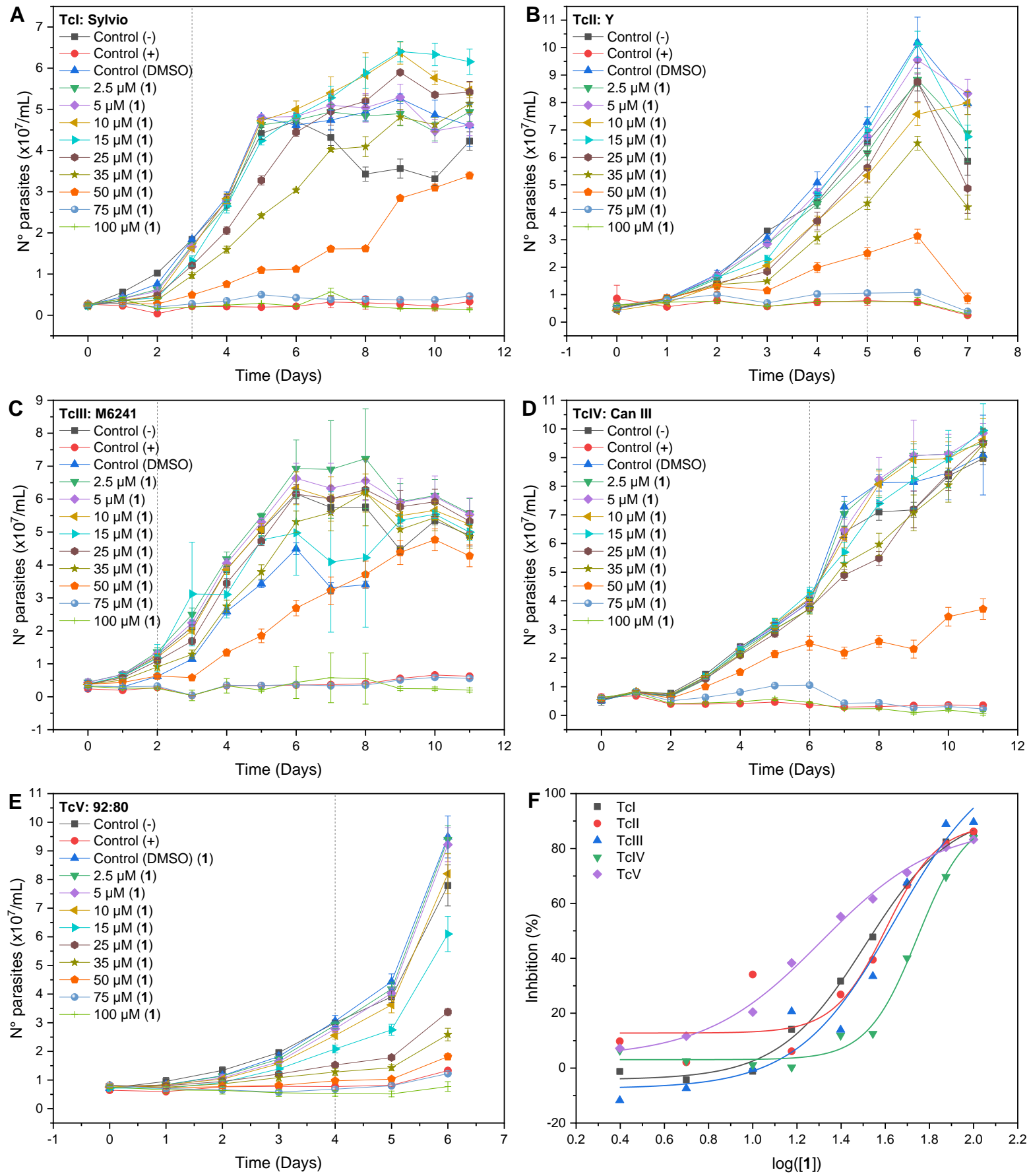

Fig. 2. Effect of the proline analogue 1 on the proliferation of the epimastigote form of $T$. cruzi Tcl TcVI. A: Tcl (Sylvio); B: Tcll (Y); C: Tclll (M6241); D: TcIV (Can III); E: TcV (92:80); F: doseresponse curves derived from the proliferation curves for each strain, when the parasites were in the mid-exponential growth phase. The time selected to perform the dose-response curves for each strain are marked in graphs A-E in a dashed grey line. Assays were performed in triplicate.

The analogues tested were active against all DTUs with $\mathrm{IC}_{50}$ values ranging between 20 and $55 \mu \mathrm{M}$ (Fig. 3). More specifically, for the 3 compounds under study, we observed that the strain belonging to TcV (92:80) was more susceptible. The strain belonging to TcIV was the most 
resistant to $\mathbf{1}$, and the strain belonging to TcVI was less susceptible to $\mathbf{3}$, when compared to the other strains. These results show that the proline analogues have a broad-spectrum action against the different $T$. cruzi DTUs. As a first conclusion, we can consider that there are no substantial differences in the activity of these compounds against the different strains assessed here. For this reason, we selected the concentration corresponding to the $\mathrm{IC}_{50}$ S for $\mathrm{TcVI}$ (CL14) as representative for further determinations (Fig. 1).

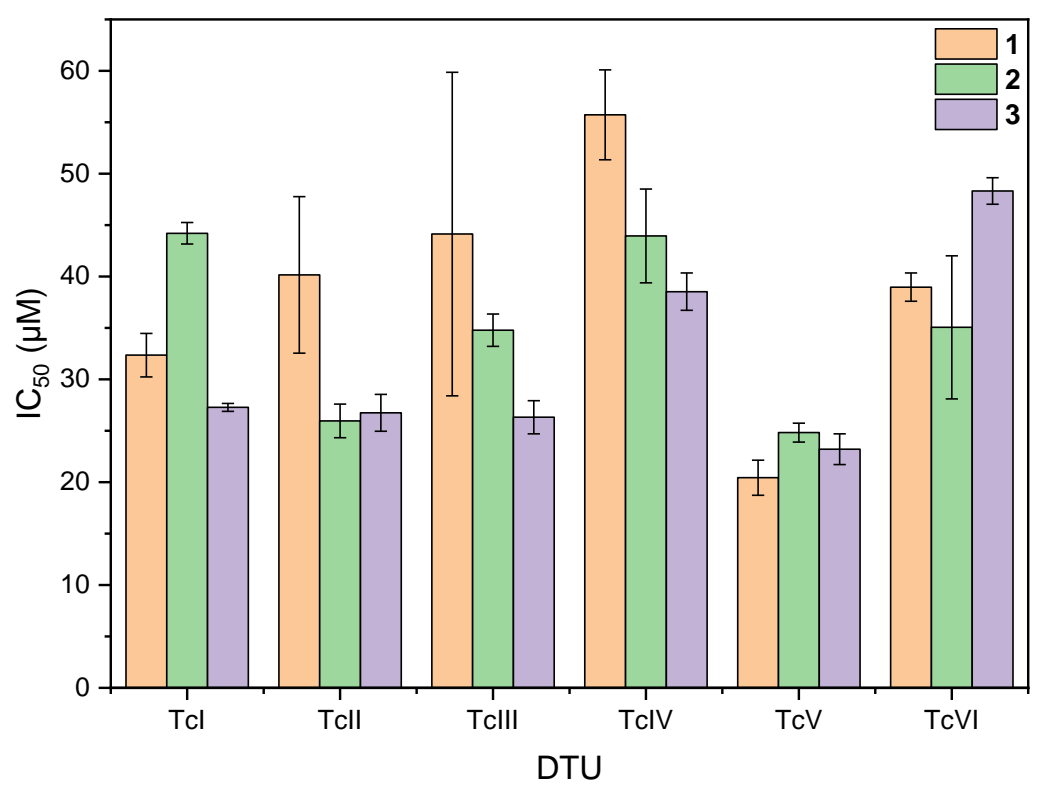

Fig. 3. Inhibitory concentration $\left(\mathrm{IC}_{50}\right)$ determined for the proline analogues $\mathbf{1 ,} \mathbf{2}$ and $\mathbf{3}$ against $T$. cruzi epimastigotes (Tcl to TcVI). Data are clusterized by DTU.

\subsection{NBD-tagged decyl analogue is internalized into $T$. cruzi epimastigotes}

In order to evaluate the possible uptake of L-proline analogue 1 by $T$. cruzi epimastigotes, we designed and synthesized a fluorescent derivative, which preserved the structural requirements that would contribute to its activity. Amino-NBD (7-amino-4-nitro-2,1,3-benzoxadiazole) was selected as fluorophore, since it has been extensively used as a fluorescent reporter of many metabolites, including cholesterol ${ }^{30}$, phospholipids ${ }^{31}$, fatty acids ${ }^{32}$ and natural products ${ }^{33}$. This group was incorporated at the end of the decyl chain to form the fluorescent probe 4 (Fig. 4). To estimate how the designed fluorescent analogue mimics 1, the most important topological descriptors were considered. To this end, $\log \mathrm{P}$, topological polar surface area (TPSA) and volume were calculated using molinspiration platform ${ }^{34}$. LogP was similar for both $(\mathbf{1}=4.62,4=5.03)$, TPSA was considerable higher for $4\left(1=60.26 \AA^{2}, 4=157.04 \AA^{2}\right)$, and the volume was bigger for 
the fluorescent analogue, as expected $\left(1=359.38 \AA^{3}, 4=484.01 \AA^{3}\right)$. Besides the differences on the volume and the TPSA, that are consequence of the NBD located on the aliphatic tail, logP was not considerably affected. In order to stablish the significance of the differences between the calculated topological descriptors of $\mathbf{1}$ and $\mathbf{4}$, we decided also to calculate the properties for previously reported NBD-tagged metabolites that have been successfully validated with transporters or permeases experiments. LogP, TPSA and volume for the NBD-tagged cholesterol ${ }^{35}$, cholic acids ${ }^{36}$, glucose ${ }^{37}$, fructose ${ }^{38}$ and spermidine ${ }^{39}$ and the native metabolites were calculated. The results (Table 1) showed similar or even higher differences for the reported NBDtagged metabolites compared to $\mathbf{1}$ and $\mathbf{4}$. Therefore, we were confident that the proposed structure could potentially be internalized by a permease.

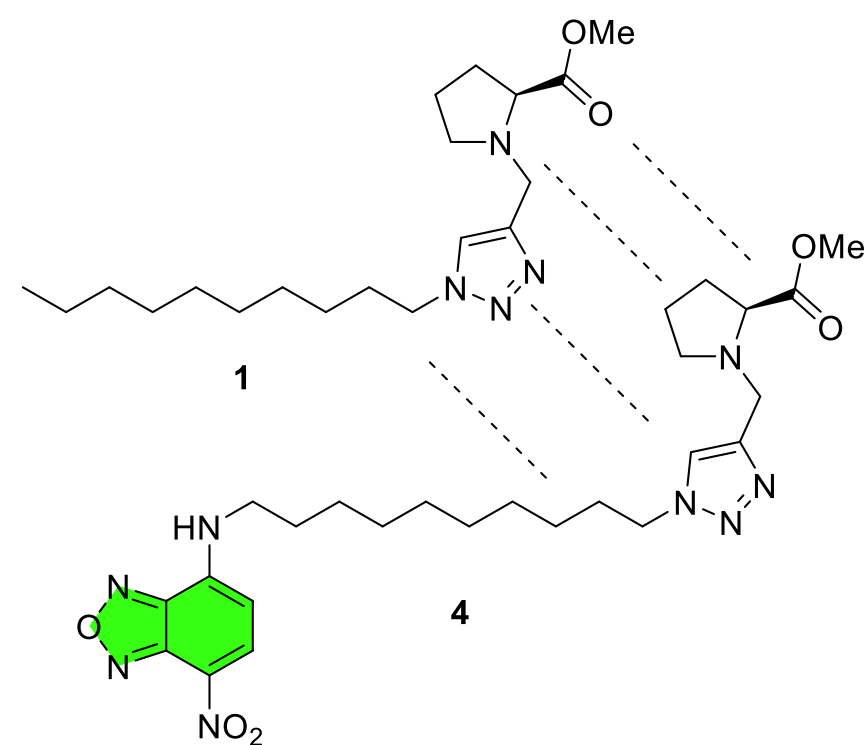

Fig. 4. Similarities between 1 and $\mathbf{4}$. The fluorescent analogue preserves the most important portion of 1

The UV-vis and fluorescent spectra of compound 4 were acquired, and the excitation and emission fluorescence maximum were $472 \mathrm{~nm}$ and $538 \mathrm{~nm}$, respectively (see Supporting Information, Figures S6 and S7). Once we set the detection parameters for compound 4, we analysed its incorporation in epimastigotes, (strain Dm28c). Parasites were incubated at different concentrations of the analogue, between 10 and $30 \mu \mathrm{M}$, for 30 minutes, and prepared for confocal microscopy. The best images were obtained for epimastigotes incubated with $25 \mu \mathrm{M}$ of 4 (Fig. 5). 


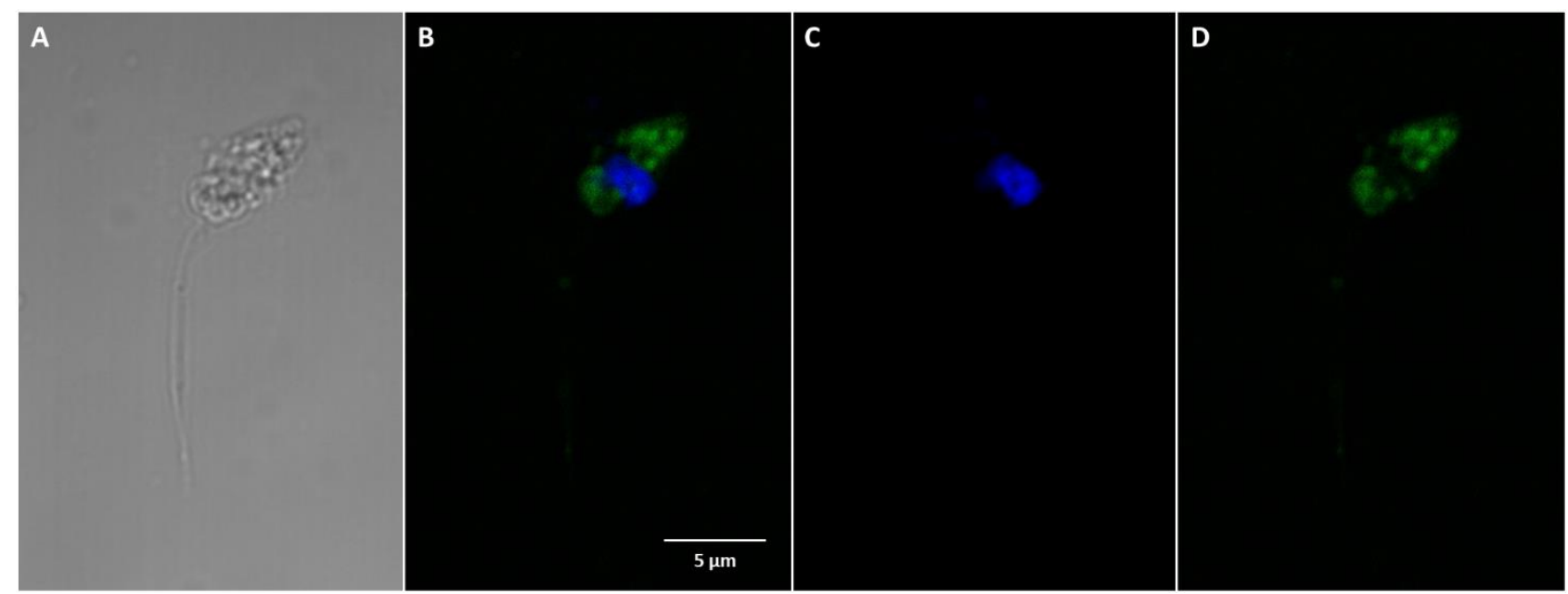

Fig. 5. Intracellular localization of compound 4 in epimastigotes of T. cruzi (Dm28c). Epimastigotes were incubated during $30 \mathrm{~min}$, at $28^{\circ} \mathrm{C}$ with $25 \mu \mathrm{M}$ of 4 . The uptake and intracellular distribution was assessed by confocal microscopy. A: differential interference contrast (DIC) microscopy. B: intracellular distribution of 4 following incubation with DAPI and 4. C: labelling with DAPI (blue). D: labelling with 4 (green). The results are representative of at least three independent experiments

The analysis of the confocal images showed that the green fluorescent signal of $\mathbf{4}$ was localized in clusters to the parasite cytoplasm and excluded from the plasmatic membrane. This result confirms that compound $\mathbf{4}$ was taken up by either passive transport across the parasite membrane or through a transporter. The pattern of the fluorescent signal of 4 suggested that this compound could be accumulated in internal vesicles. 
Table 1. Physicochemical parameters of metabolites and their NBD analogues

\begin{tabular}{|c|c|c|c|c|c|c|c|c|c|}
\hline Compound & miLogP & TPSA $\left(\AA^{2}\right)$ & Volume $\left(\AA^{3}\right)$ & MW & natoms & nON & nOHNH & nviolations & nrotb \\
\hline & 4.62 & 60.26 & 359.38 & 350.51 & 25 & 6 & 0 & 0 & 13 \\
\hline & 5.03 & 157.04 & 484.01 & 528.61 & 38 & 13 & 1 & 3 & 17 \\
\hline & 7.62 & 20.23 & 423.13 & 386.66 & 28 & 1 & 1 & 1 & 5 \\
\hline & 6.50 & 117.00 & 463.97 & 494.64 & 36 & 8 & 2 & 1 & 5 \\
\hline & 3.33 & 97.98 & 406 & 408.58 & 29 & 5 & 4 & 0 & 4 \\
\hline & 5.94 & 174.53 & 522 & 570.69 & 41 & 11 & 4 & 3 & 7 \\
\hline & & & & & & & & & \\
\hline
\end{tabular}




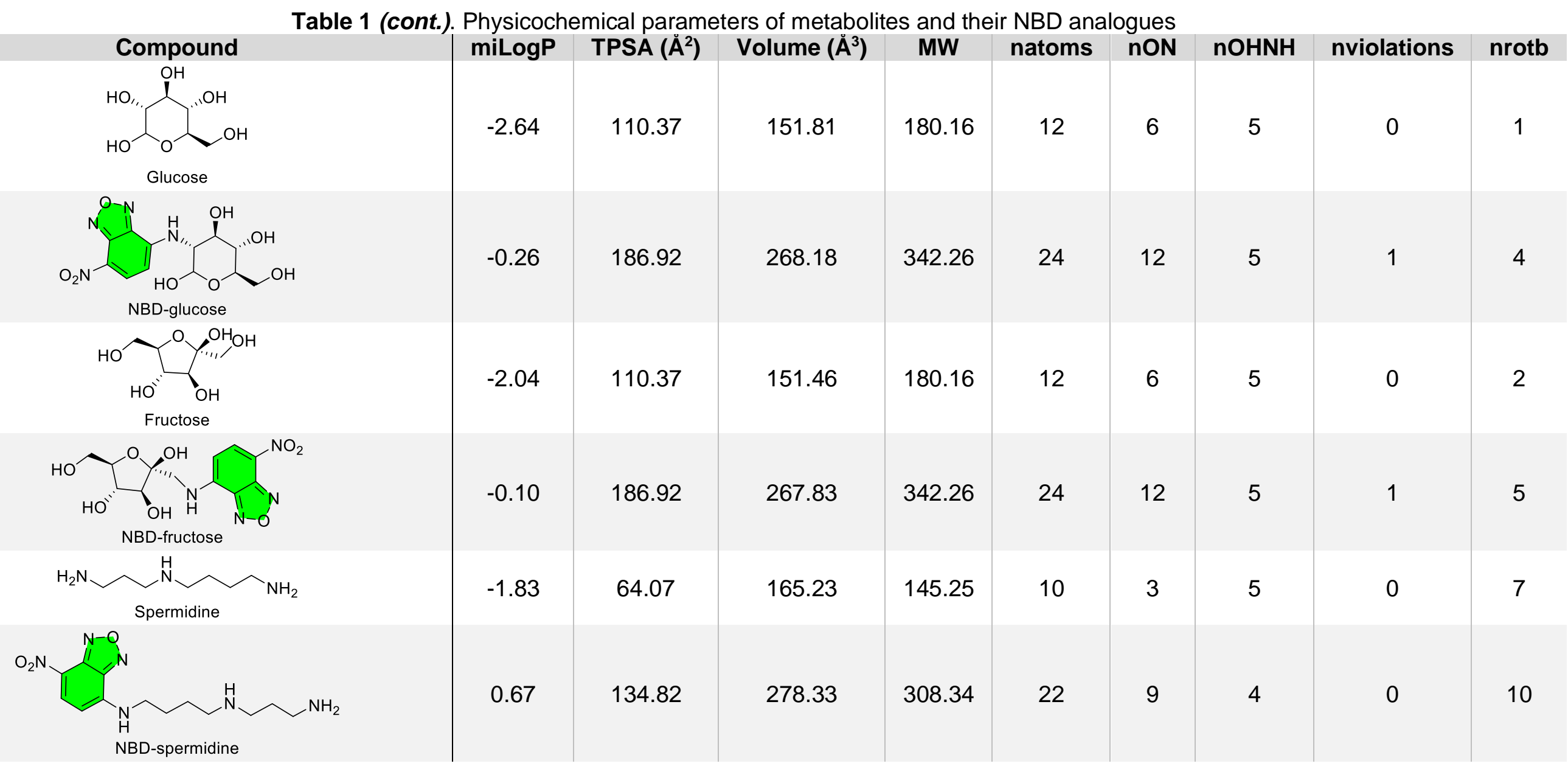




\subsection{Triazole moiety is crucial for activity in the decyl-substituted analogue}

In order to determine the role of triazole moiety in the activity of compound $\mathbf{1}$, non-triazolic analogues 5 and 6 (Fig. 6) were tested against CL14 epimastigotes. We chose $\mathrm{N}$-substitution with alkyl chains of $10(5)$ and 13 (6) carbons, in a way that compound 5 has the same alkyl substituent, and compound 6 preserves the same chain length as 1. None of these compounds had trypanocidal activity at concentrations up to $(100 \mu \mathrm{M})$, indicating that the triazole moiety plays a critical role for the anti-T. cruzi activity.

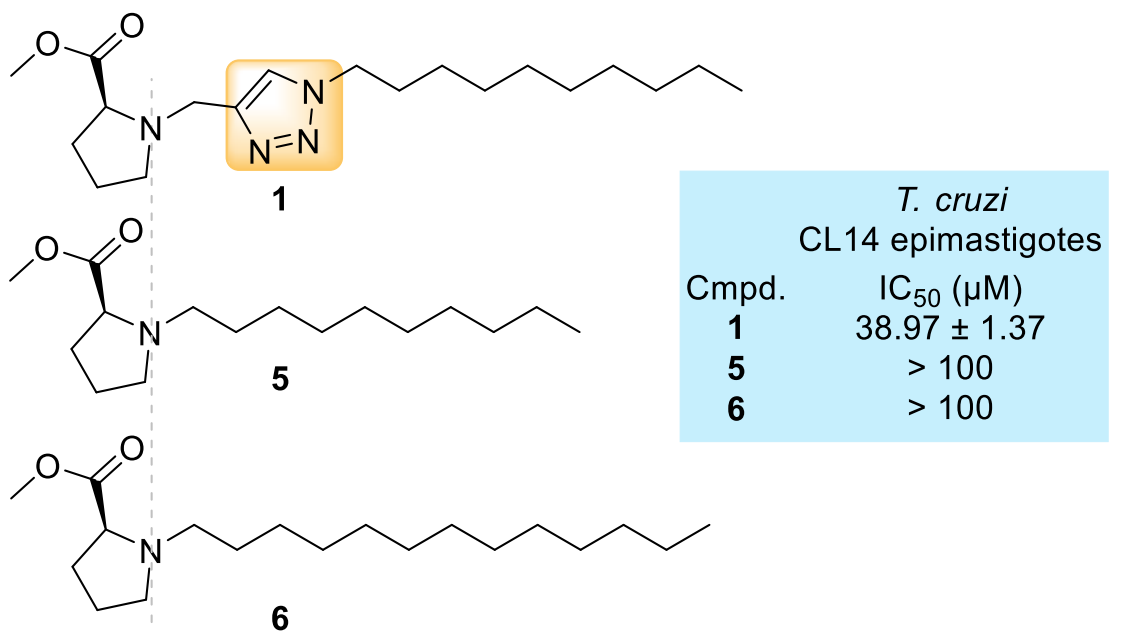

Fig. 6. Non-triazolic L-proline analogues

\subsection{Farnesyl analogue promotes necrosis at high concentration}

Programmed cell death (PCD) refers to broad spectrum processes leading to cell death. Their common feature is their development through an organized and ordered sequence of events leading to morphological and biochemical changes of the cell. One of the landmarks of these processes consists of the exposure of phosphatidylserine on the extracellular leaflet of the plasma membrane. In order to investigate the effect the compounds assayed herein are having in the cell death mechanism, acting through the induction of PCD we analysed the presence of phosphatidylserine at the external surface of the parasite, as well as the cell membrane rupture by using FITC-labelled Annexin-V/propidium iodide double labelling and cytometry analysis. The parasites (CL14 epimastigotes) were incubated in the presence of the inhibitors 1, 2 and $\mathbf{3}$, at their 
respective $\mathrm{IC}_{50}$ and $\mathrm{IC}_{80}$ concentrations, for 72 hours, and Annexin V-FITC /propidium iodide labelling was added to perform the flow cytometry analysis (Fig. 7).

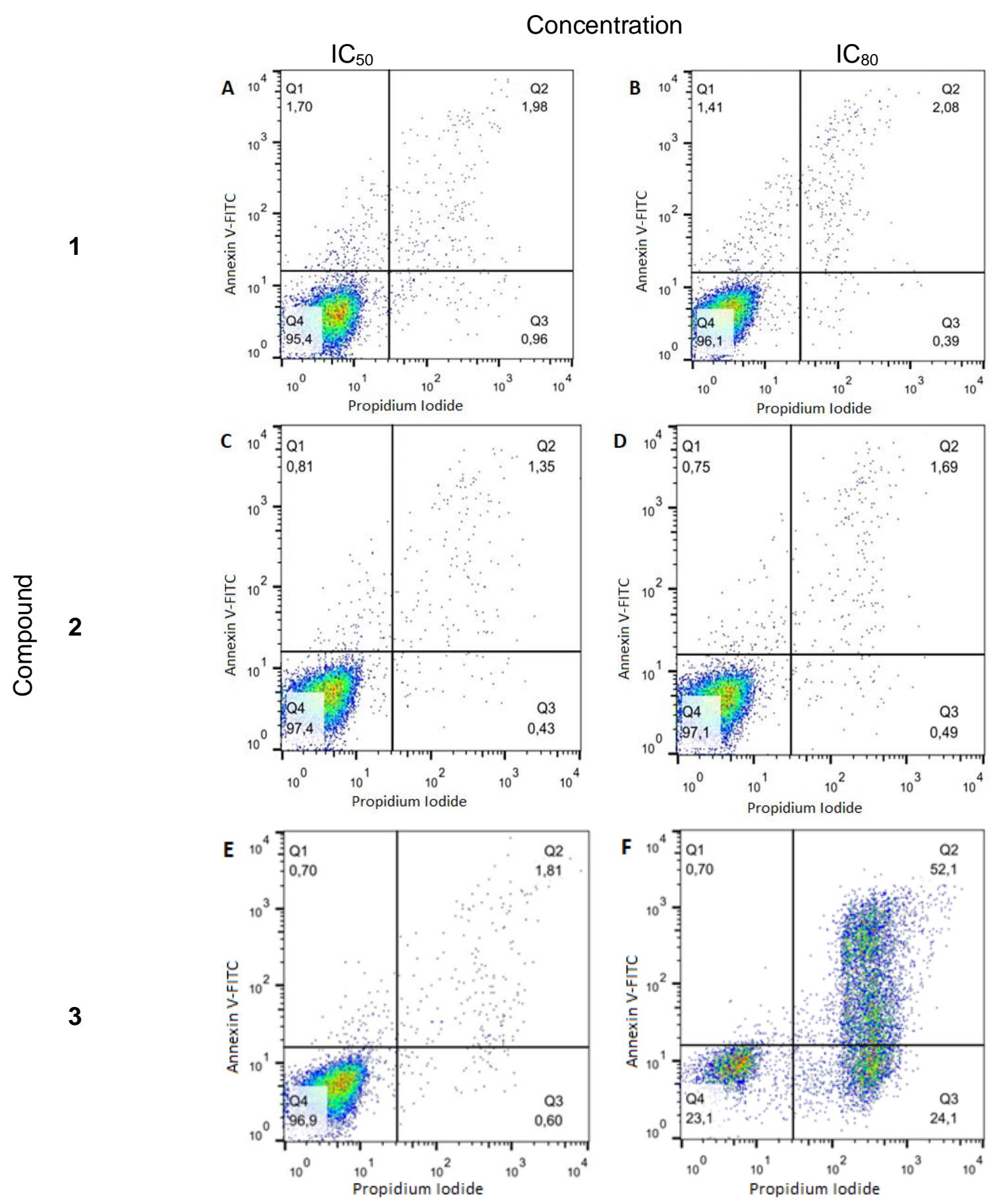

Fig. 7. Flow cytometry results $T$. cruzi epimastigotes (CL14) treated with compounds 1-3. A, B: Compound $1\left(\mathrm{IC}_{50}=39 \mu \mathrm{M}, \mathrm{IC}_{80}=74 \mu \mathrm{M}\right)$; C, D: Compound $2\left(\mathrm{IC}_{50}=35 \mu \mathrm{M}, \mathrm{IC}_{80}=54 \mu \mathrm{M}\right)$; E, F: Compound $\mathbf{3}\left(\mathrm{IC}_{50}=49 \mu \mathrm{M}, \mathrm{IC}_{80}=116 \mu \mathrm{M}\right)$. Panels A, C, E [cmpd] $=\mathrm{IC}_{50}$; Panels $\mathbf{B}, \mathbf{D}, \mathbf{F}$ [cmpd] $=$ $\mathrm{IC}_{80}$. The subtraction corresponding to the percentage of cell death obtained in each quadrant for the control has already been carried out

As shown in Fig. 7, all 3 compounds showed a labelling pattern different from that expected for PCD or necrosis at concentrations corresponding to their $\mathrm{IC}_{50}$, since more than $95 \%$ of cells remained unlabelled with either Annexin V-FITC or propidium iodide. When $\mathbf{1}$ and $\mathbf{2}$ were 
administered at a concentration equal to their respective $\mathrm{IC}_{80}$, the same effect was observed. But, in treatments with 3 at its $\mathrm{IC}_{80}$, cell membrane rupture was detected in $76 \%$ of cells, indicating that necrosis started to gain relevance when concentration of this compound was raised.

\subsection{Farnesyl analogue does not induce significant changes in the parasite metabolism}

Considering the important role L-proline has on the energetic metabolism in T. cruzi, and having proved that some of the proline analogues studied here affect the proline uptake and transport in epimastigotes ${ }^{22,23}$, we decided to study how these analogues affect $T$. cruzi the excretion of end-products of the metabolism. To this end, parasites $\left(0.5 \times 10^{6}\right.$ epimastigotes $/ \mathrm{mL}$, strain Dm28c) maintained in DMEM (high glucose concentration) $2 \%$ SFB were treated with analogues $\mathbf{1 , 2}$ or $\mathbf{3}$ at a concentration corresponding to their $\mathrm{IC}_{50}$. The obtained spent medium was analysed by NMR spectroscopy. In this case we focused our analysis on the quantitative detection of lactate (Lac), acetate (AcO), pyruvate (Pyr) and succinate (Suc), and the amino acids alanine (Ala) and glycine (Gly), since most of them have been described as being the most relevant metabolites excreted by $T$. cruzi, under normal growth conditions ${ }^{40}$. Regarding ethanol as an excreted metabolite, previous reports showed that most of $T$. cruzi strains do not possess the necessary enzymes to produce that metabolite ${ }^{40}$. However, certain clones of the Bolivian strain of T. cruzi that secreted $\mathrm{EtOH}$ have been described ${ }^{41}$. The results from this assay are shown in Fig. 8. 

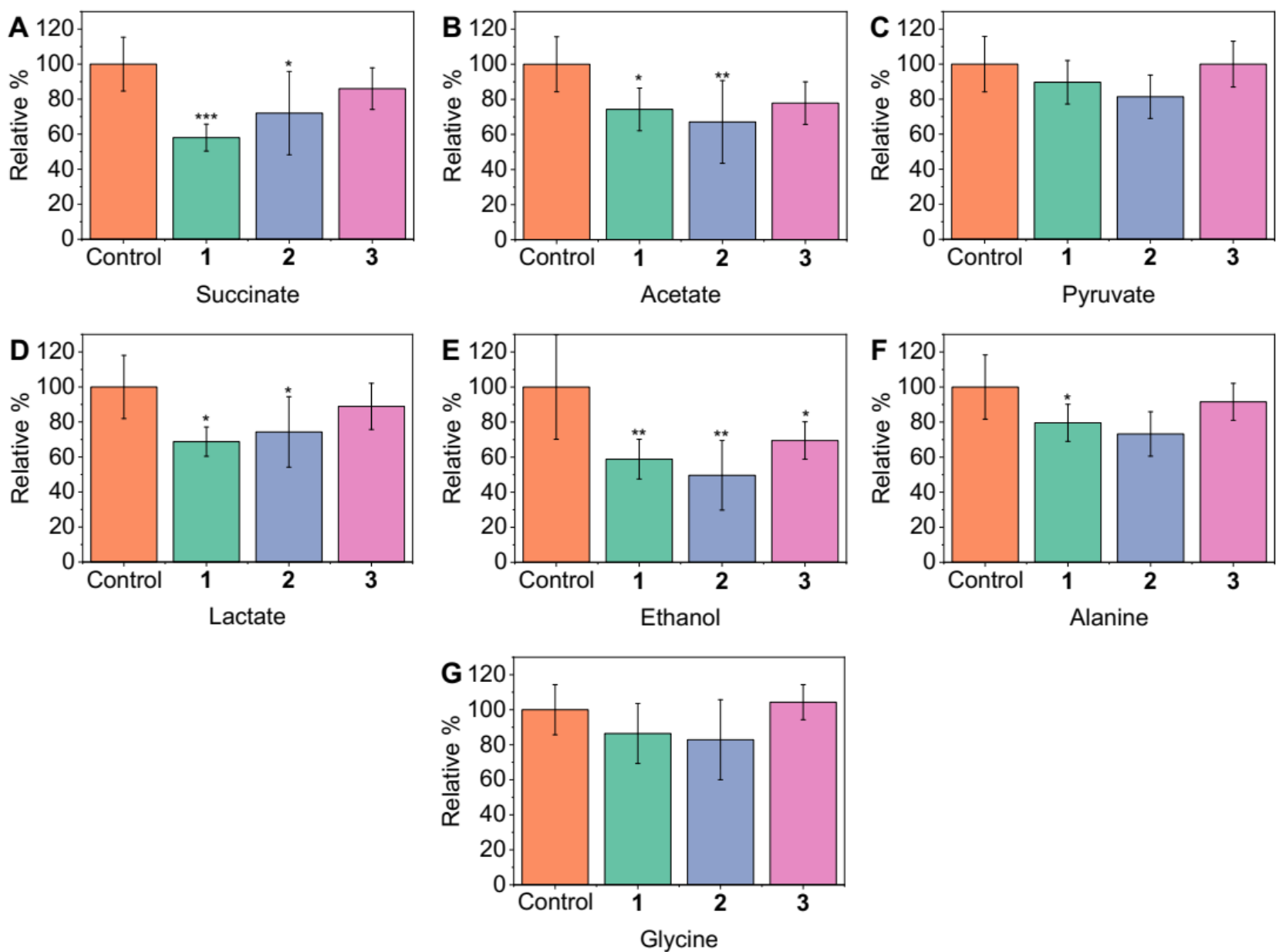

Fig. 8. Metabolic change determined for T. cruzi epimastigotes treatment with 1, 2 and $\mathbf{3}$. All results are indicated as relative percentage, respect to the non-inhibited control. Significance level: ${ }^{*} \mathrm{P}<0.05$; ${ }^{*} \mathrm{P}<0.01$; ${ }^{* *} \mathrm{P}<0.001$, compared to control. Metabolites analysed: A: Succinate; $\mathbf{B}$ : Acetate; C: Pyruvate; D: Lactate; E Ethanol; F: Alanine; G: Glycine.

Our results showed that compounds $\mathbf{1}$ and $\mathbf{2}$ induce a similar metabolic behaviour, producing decreases in the amount of $\mathrm{Lac}, \mathrm{AcO}, \mathrm{EtOH}$ and Suc. Importantly, a higher difference in the amounts of Suc was detected for the treatment with compound $\mathbf{1}$ when compared to its control. Compound $\mathbf{3}$ did not produce any significant changes in the metabolism respect to the control, since it only caused a significant decrease for the excretion of $\mathrm{EtOH}$.

\section{Discussion}

The relevance of proline for $T$. cruzi metabolism has been established for the first time by the end of the 1950 s $^{42}$, when the ability of epimastigotes to oxidize this amino acid was demonstrated. The relationship between amino acid consumption and energy metabolism in trypanosomatids was 
later described ${ }^{43}$, having proposed that the enzymes involved in these pathways could constitute targets for the development of new chemotherapeutic agents ${ }^{44}$.

Here we showed that three proline analogues were active against different $T$. cruzi strains representing the six DTUs (Fig. 3). Interestingly, the strain belonging to TcV was more sensitive to this type of compounds. On the other hand, the strain belonging to TcVI proved to be less sensitive to the analogue $\mathbf{3}$, while the strain belonging to TcIV was less sensitive to the analogue 1. A Nevertheless, it is not easy to derive conclusions from such subtle differences. For example, previous studies have shown differences in the susceptibility to benznidazole among different strains. However, nowadays it is considered that differences observed in clinical trials are more likely due to environmental factors than due to intrinsic biological differences of the strains ${ }^{4}$. Based on those precedents, the tested compounds displayed similar effects regardless the strain. Therefore, these compounds show broad-spectrum activity against the different $T$. cruzi DTUs.

It has been previously reported that the analogue $\mathbf{1}$ was not as effective as $\mathbf{3}$ as a proline transport inhibitor ${ }^{23}$. Indeed, those differences were explained based on the restricted conformation of compound $\mathbf{3}$ due to the multiple double bonds of the farnesyl chain. Additionally, its test against a transgenic parasite overexpressing the TcAAAP069 proline permease has shown that compound 3 was able to inhibit the proline uptake after $1 \mathrm{~h}$ incubation ${ }^{23}$. This result suggested that the farnesyl derivative $\mathbf{3}$ was not internalized by the parasite, acting as a blocker of the transporter from the extracellular side.

Compound 1 was tagged with NBD to make the fluorescent analogue 4 to track the uptake and its intracellular fate. Remarkably, this strategy is almost unexplored for antiparasitic drugs action mechanism studies, with few exceptions including miltefosine ${ }^{45}$, artemisinin ${ }^{46}$ and chloroquine ${ }^{47}$. The green fluorescent signal of the NBD derivative of compound $\mathbf{1}$ (Fig. 5) was localized to the parasite cytoplasm in clusters resembling intra-organelle localization. The fact that the compound was indeed transported into the cell together with the proline uptake inhibition ${ }^{22}$, allowed us to postulate that: i. compound $\mathbf{1}$ (from which compound $\mathbf{4}$ is derived) could be competing with the amino acid incorporation, and ii. compound $\mathbf{1}$ has a different inhibition mechanism than 3. 
Variations of compound $\mathbf{1}$ were used as well to identify critical moieties for its trypanocidal activity. Compounds 5 and 6 (Fig. 6) were synthesized mimicking compound 1 but without the triazole moiety. Their lack of effect on the parasite led us to conclude that the triazole is critical for the trypanocidal activity. The 1,2,3-triazoles are part of a wide variety of biologically relevant structures, and are capable of mimic an amide bond, being biocompatible and very stable structures ${ }^{48}$. Although 1,2,3-triazoles are mostly used as linkers in biologically active structures, they can also interact with different biological targets. In addition, they are nowadays also recognized as a pharmacophoric structure ${ }^{49}$. We have previously designed and synthesized isoprenylic 1,4-disubstituted 1,2,3-triazoles as T. cruzi CYP51 inhibitors ${ }^{50}$. We found that the 1,2,3triazole analogue holding an E,E-farnesyl substituent on $\mathrm{N} 1$ and a methyl carboxylate on $\mathrm{C} 4$ (compound 7, Fig. 9) improved the trypanocidal activity, compared to alkyl substituent on the C4 position. Those findings lead us to conclude that the carboxylate on C4 plays an important role improving on the activity against $T$. cruzi. In this sense, for compound $\mathbf{1}$, it is expected that the proline-triazole hybrid would be responsible for its action, where the methyl ester group would also play an important role. On the other hand, comparing the methyl ester triazole 7 with proline analogue 3, it seems clear that the mere replacement of the methyl ester by a methyl prolinate is producing a change in the mode of action. Indeed, compound 7 proved to bind CYP51 ${ }^{50}$ without evidence that indicates that this compound is not internalized into the parasite, while compound $\mathbf{3}$ binds and inhibits the proline permease from outside the cell, not being internalized by the parasite 23.

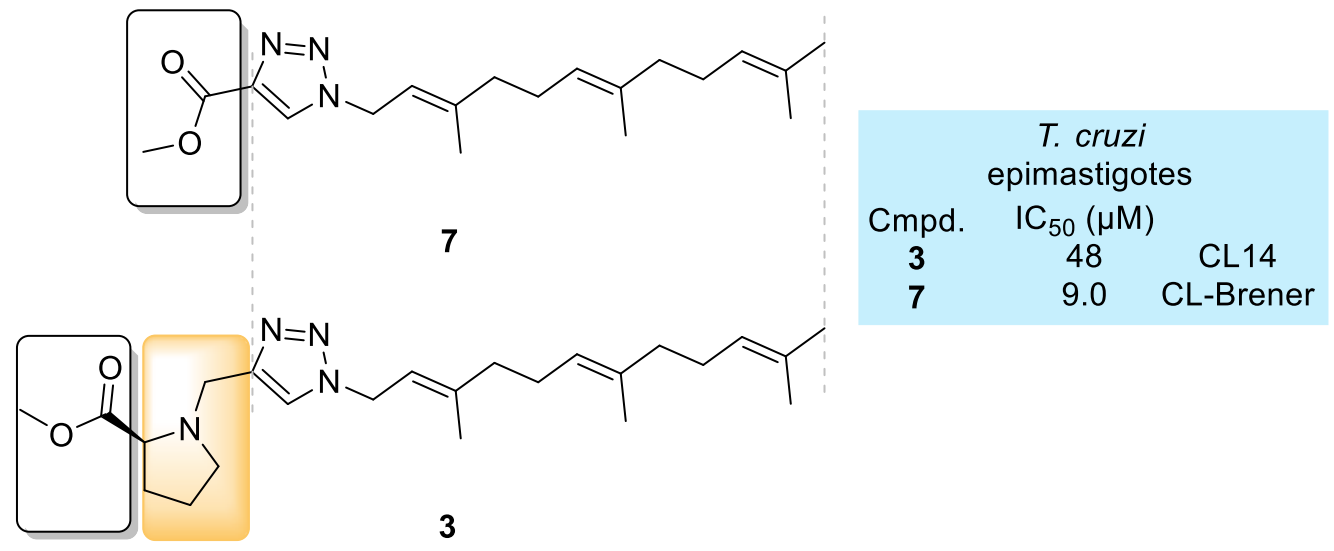

Fig. 9. Farnesyl triazoles active against T. cruzi 
When cell death type was studied, we found that compound 3 can produce necrosis at a high concentration (i.e., $\mathrm{IC}_{80}$ ), but this effect was not observed at a lower concentration. From the transport inhibition assays ${ }^{23}$, we learned that compound 3 acts by blocking the proline transporter TcAAAP069, so this analogue is not incorporated into the epimastigotes. Taking this into account, when concentration of $\mathbf{3}$ is increased, the cell membrane begins to saturate, and a change in its permeability is possible, leading to a necrotic cell death. The fact that compounds $\mathbf{1}$ and $\mathbf{2}$, either at low or high concentrations, did not show death features (Fig. 7) led us to propose a trypanostatic rather than a trypanocidal mode of action.

The ability of $T$. cruzi to metabolize amino acids has been reported ${ }^{9,42,51}$. Regarding proline, it is oxidized in two enzymatic steps to glutamate, which can be transported from the cytoplasm to the mitochondria and incorporated into the tricarboxylic acid (TCA) cycle ${ }^{44}$. Proline oxidation has been described to occur in the mitochondria, stimulating cellular respiration and carrying out ATP synthesis through the oxidative phosphorylation process ${ }^{15,52}$. Since $T$. cruzi does not have intracellular glycogen as an energy reserve, glucose is obtained from the extracellular environment through a transport system and then it is catabolized, producing reduced metabolites, mainly succinate and L-alanine ${ }^{43}$. In the present work, we set up to determine if the proline analogues 1 3 were capable of interfering with the normal metabolic pathway in T. cruzi (Scheme 1). An approach was made to follow-up by NMR the different metabolites excreted by $T$. cruzi when treated with $\mathbf{1}-\mathbf{3}$ at their $\mathrm{IC}_{50}$ S. Observing the results from the metabolomics assays (Fig. $\mathbf{8}$ ), it is appreciable that compounds $\mathbf{1}$ and $\mathbf{2}$ had a similar behaviour, causing a significant decrease in most metabolites, and this could be due to a redox imbalance in the mitochondria, induced by the incorporation of the analogues to the parasite. The analogue $\mathbf{3}$ did not show significant changes in the metabolic values studied, as expected. As we proposed in our previous work ${ }^{23}$, this compound would be acting by blocking the transporter. This would cause neither proline nor the analogue to enter into the cell, and would provoke a differential response. We could expect that once the glucose is consumed, the parasite would not have access to the proline of the medium and this would cause its death. 


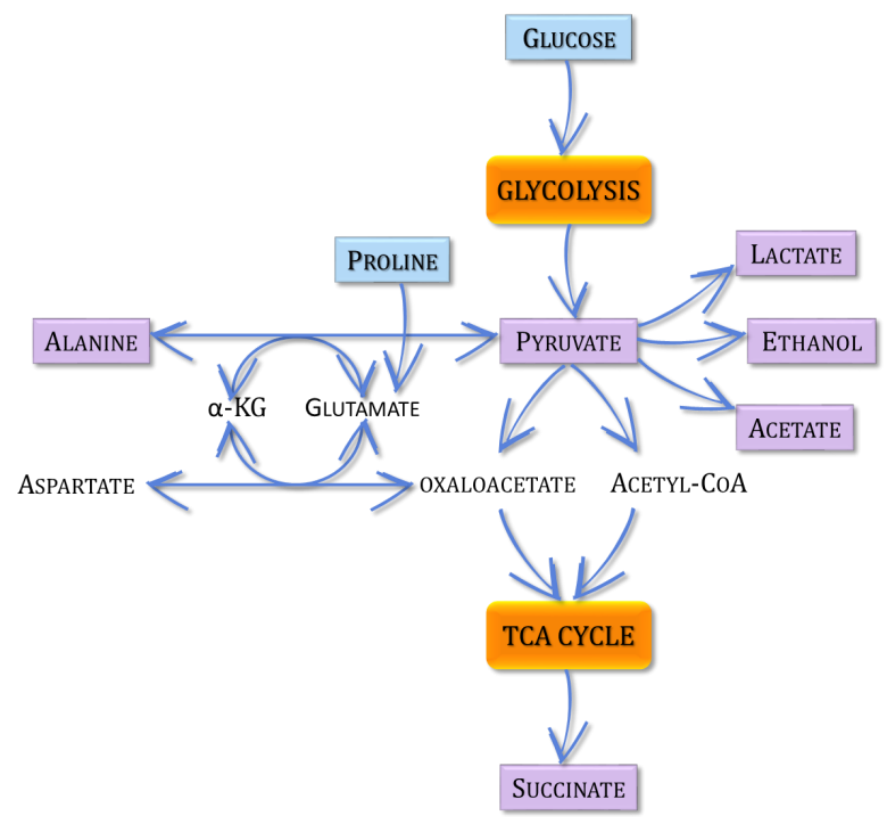

Scheme 1. Central metabolism in T. cruzi epimastigotes. Metabolites under study in this work are highlighted in purple. Glucose and Proline (light blue) are introduced from extracellular media

Our findings exposed in this work reinforce our initial hypothesis, where we proposed that compounds 1 and $\mathbf{3}$ have different modes of action. On the one hand, analogue $\mathbf{1}$ showed a similar response than 2 in the cell death type and metabolomics assays, but 1 proved to inhibit proline uptake and transport, effect not observed in $\mathbf{2}^{22,23}$. Therefore, $\mathbf{1}$ and $\mathbf{2}$ may be acting on the same in-cell target, with the difference that $\mathbf{1}$ may be taking advantage of the proline transport system to be internalized. On the other hand, compound 3, showed a necrotic death pathway at high concentrations, along with poor, or no change in the metabolic cycle, respect to the non-inhibited control. Both assays indicate that the most plausible mode of action for this analogue takes place form the extracellular space, in accordance with our previous studies where $\mathbf{3}$ proved to bind the proline permease and not being internalized ${ }^{23}$.

\section{Conclusion}

In this work we demonstrated that we were able to produce proline analogues that effect their action by two different mechanisms. Compound $\mathbf{1}$ may be acting by being recognized and incorporated to the parasite by the proline transport system, and inhibition could be due to the proline - triazole moiety interacting with an in-cell target. This compound most likely competes with proline to enter to the parasite. Compound $\mathbf{3}$ blocks the proline transport system and produces a 
proline depletion in the parasite. Since proline is fundamental for many biological processes in $T$. cruzi, 3 provokes a parasite misfunction, which leads to a necrotic death.

Both modes of action open doors to different inhibition strategies. The first one has the potential for the design of new compounds with Trojan horse mode of action, derived from already known inhibitors, but improving permeability properties by the addition of proline as a recognition motif for the permease, and, in consequence, increase the inhibitor internalization, previously made by passive diffusion. The second mode of action involves a direct inhibition of the proline permease, and proved that proline depletion can lead to loss of cell viability. Further structural optimization of analogue $\mathbf{3}$ will lead us to a compound with a high potency with scarce to nonadverse effects. This will lead to a better understanding of the active site and ligand - target interactions.

\section{Supplementary Information}

The online version contains supplementary material available at https://doi.org/

\section{Funding}

The authors wish to express their gratitude to UNR (Universidad Nacional de Rosario, Bio503), Agencia Nacional de Promoción Científica y Tecnológica (ANPCyT PICT- 2017-2096 awarded to GL) and Fundação de Amparo à Pesquisa do Estado de São Paulo grants 2016/06034-2 (awarded to AMS) and Conselho Nacional de Pesquisas Científicas e Tecnológicas (CNPq) grants 404769/2018-7 and 308351/2013-4 (awarded to AMS). The research leading to these results has, in part, received funding from the UK Research and Innovation via the Global Challenges Research Fund under grant agreement A Global Network for Neglected Tropical Diseases grant number MR/P027989/1. GL and JC are members of the Research Career of the Consejo Nacional de Investigaciones Científicas y Técnicas of Argentina (CONICET). MSB, LF, and LP thanks CONICET for the award of a Fellowship.

Declarations of interest: none.

\section{Credit Author Statement}


María Sol Ballari: Formal analysis; Investigation; Validation; Visualization; Writing - original draft. Lucia Fargnoli: Formal analysis; Investigation; Validation; Visualization. Lucas Pagura: Formal analysis; Investigation; Validation. Julia A. Cricco: Conceptualization; Methodology; Resources; Writing - review \& editing. Ariel M. Silber: Conceptualization; Funding acquisition; Methodology; Resources; Writing - review \& editing. Guillermo R. Labadie: Conceptualization; Data curation; Funding acquisition; Methodology; Project administration; Resources; Supervision; Writing - review \& editing.

\section{References}

(1) Zingales, B., Andrade, S. G., Briones, M. R. S., Campbell, D. A., Chiari, E., Fernandes, O., Guhl, F., Lages-Silva, E., Macedo, A. M., Machado, C. R., Miles, M. A., Romanha, A. J., Sturm, N. R., Tibayrenc, M., and Scijman, A. G. (2009) A new consensus for Trypanosoma cruzi intraspecific nomenclature: second revision meeting recommends Tcl to TcVI. Mem. Inst. Oswaldo Cruz 104, $1051-1054$.

(2) Campbell, D. A., Westenberger, S. J., and Sturm, N. R. (2004) The Determinants of Chagas Disease: Connecting Parasite and Host Genetics. Curr. Mol. Med. 4, 549-562.

(3) Miles, M. A., Llewellyn, M. S., Lewis, M. D., Yeo, M., Baleela, R., Fitzpatrick, S., Gaunt, M. W., and Mauricio, I. L. (2009) The molecular epidemiology and phylogeography of Trypanosoma cruzi and parallel research on Leishmania: Looking back and to the future. Parasitology 136, 15091528.

(4) Zingales, B. (2018) Trypanosoma cruzi genetic diversity: Something new for something known about Chagas disease manifestations, serodiagnosis and drug sensitivity. Acta Trop. 184, 38-52.

(5) Zingales, B., Miles, M. A., Campbell, D. A., Tibayrenc, M., Macedo, A. M., Teixeira, M. M. G., Schijman, A. G., Llewellyn, M. S., Lages-Silva, E., Machado, C. R., Andrade, S. G., and Sturm, N. R. (2012) The revised Trypanosoma cruzi subspecific nomenclature: Rationale, epidemiological relevance and research applications. Infect. Genet. Evol. 12, 240-253.

(6) Lages-Silva, E., Crema, E., Ramirez, L. E., Macedo, A. M., Pena, S. D., and Chiari, E. (2001) 
Relationship between Trypanosoma cruzi and human chagasic megaesophagus: Blood and tissue parasitism. Am. J. Trop. Med. Hyg. 65, 435-441.

(7) Barros-Álvarez, X., Cáceres, A. J., Michels, P. A. M., Concepción, J. L., and Quiñones, W. (2014) The phosphoglycerate kinase isoenzymes have distinct roles in the regulation of carbohydrate metabolism in Trypanosoma cruzi. Exp. Parasitol. 143, 39-47.

(8) Barisón, M. J., Rapado, L. N., Merino, E. F., Pral, E. M. F., Mantilla, B. S., Marchese, L., Nowicki, C., Silber, A. M., Cassera, M. B., Nakamura Rapado, L., Merino, E. F., Furusho Pral, E. M., Suarez Mantilla, B., Marchese, L., Nowicki, C., Silber, A. M., and Cassera, M. B. (2017) Metabolomics profiling reveals a finely tuned, starvationinduced metabolic switch in Trypanosoma cruzi epimastigotes. J. Biol. Chem. 292, 8964-8977.

(9) Sylvester, D., and Krassner, S. M. (1976) Proline metabolism in Trypanosoma cruzi epimastigotes. Comp. Biochem. Physiol. Part B Comp. Biochem. 55, 443-447.

(10) Contreras, V. T., Salles, J. M., Thomas, N., Morel, C. M., and Goldenberg, S. (1985) In vitro differentiation of Trypanosoma cruzi under chemically defined conditions. Mol. Biochem. Parasitol. $16,315-327$.

(11) Homsy, J. J., Granger, B., and Krassner, S. M. (1989) Some factors inducing formation of metacyclic stages of Trypanosoma cruzi. J. Protozool. 36, 150-153.

(12) Tonelli, R. R., Silber, A. M., Almeida-de-Faria, M., Hirata, I. Y., Colli, W., and Alves, J. M. (2004) L-Proline is essential for the intracellular differentiation of Trypanosoma cruzi. Cell. Microbiol. 6, 733-741.

(13) Silber, A. M., Tonelli, R. R., Lopes, C. G., Cunha-e-Silva, N., Torrecilhas, A. C. T., Schumacher, R. I., Colli, W., and Alves, M. J. M. (2009) Glucose uptake in the mammalian stages of Trypanosoma cruzi. Mol. Biochem. Parasitol. 168, 102-108.

(14) Magdaleno, A., Ahn, I. Y., Paes, L. S., and Silber, A. M. (2009) Actions of a proline analogue, L-thiazolidine-4-carboxylic acid (T4C), on Trypanosoma cruzi. PLoS One 4.

(15) Paes, L. S., Mantilla, B. S., Menezes Zimbres, F., Furusho Pral, E. M., Diogo de Melo, P., 
Tahara, E. B., Kowaltowski, A. J., Elias, M. C., and Silber, A. M. (2013) Proline dehydrogenase regulates redox state and respiratory metabolism in Trypanosoma cruzi. PLoS One 8, e69419.

(16) Saye, M., Miranda, M. R., Girolamo, F. Di, De Los Milagros Cámara, M., and Pereira, C. A. (2014) Proline modulates the trypanosoma cruzi resistance to reactive oxygen species and drugs through a novel D, L-Proline transporter. PLoS One 9.

(17) Martins, R. M., Covarrubias, C., Galvez Rojas, R., Silber, A. M., and Yoshida, N. (2009) Use of L-proline and ATP production by Trypanosoma cruzi metacyclic forms as requirements for host cell invasion. Infect. Immun. 77, 3023-3032.

(18) Mantilla, B. S., Paes, L. S., Pral, E. M. F., Martil, D. E., Thiemann, O. H., Fernández-Silva, P., Bastos, E. L., and Silber, A. M. (2015) Role of $\Delta 1$-pyrroline-5-carboxylate dehydrogenase supports mitochondrial metabolism and host-cell invasion of Trypanosoma cruzi. J. Biol. Chem. 290, 77677790.

(19) Marchese, L., Olavarria, K., Mantilla, B. S., Avila, C. C., Souza, R. O. O., Damasceno, F. S., Elias, M. C., and Silber, A. M. (2020) Trypanosoma cruzi synthesizes proline via a $\Delta 1$-pyrroline-5carboxylate reductase whose activity is fine-tuned by NADPH cytosolic pools. Biochem. J. 477, $1827-1845$.

(20) Silber, A. M., Tonelli, R. R., Martinelli, M., Colli, W., and Alves, M. J. M. (2002) Active transport of L-proline in Trypanosoma cruzi. J. Eukaryot. Microbiol. 49, 441-446.

(21) Reina-San-Martin, B., Degrave, W., Rougeot, C., Cosson, A., Chamond, N., Cordeiro-daSilva, A., Arala-Chaves, M., Coutinho, A., and Minoprio, P. (2000) A B-cell mitogen from a pathogenic trypanosome is a eukaryotic proline racemase. Nat. Med. 6, 890-897.

(22) Fargnoli, L., Panozzo-Zénere, E., Pagura, L., Barisón, M. J., Cricco, J. A., Silber, A. M., and Labadie, G. R. (2020) Targeting L-proline uptake as new strategy for anti-chagas drug development. Front. Chem. 8, 696.

(23) Sayé, M., Fargnoli, L., Reigada, C., Labadie, G. R., and Pereira, C. A. (2017) Evaluation of proline analogs as trypanocidal agents through the inhibition of a Trypanosoma cruzi proline 
transporter. Biochim. Biophys. Acta (BBA)-General Subj. 1861, 2913-2921.

(24) Bouvier, L. A., Silber, A. M., Galvão Lopes, C., Canepa, G. E., Miranda, M. R., Tonelli, R. R., Colli, W., Alves, M. J. M., and Pereira, C. A. (2004) Post genomic analysis of permeases from the amino acid/auxin family in protozoan parasites. Biochem. Biophys. Res. Commun. 321, 547-556.

(25) Camargo, E. P. (1964) Growth and Differentiation in Trypanosoma Cruzi. I. Origin of metacyclic trypanosomes in liquid media. Rev. Inst. Med. Trop. Sao Paulo.

(26) Merli, M. L., Pagura, L., Hernández, J., Barisón, M. J., Pral, E. M. F., Silber, A. M., and Cricco, J. A. (2016) The Trypanosoma cruzi Protein TcHTE Is Critical for Heme Uptake. PLoS Negl. Trop. Dis. $10,1-18$.

(27) Schneider, C. A., Rasband, W. S., and Eliceiri, K. W. (2012) NIH Image to ImageJ: 25 years of image analysis. Nat. Methods 9, 671-675.

(28) Jimenez, V., Paredes, R., Sosa, M. A., and Galanti, N. (2008) Natural programmed cell death in T. cruzi epimastigotes maintained in axenic cultures. J. Cell. Biochem. 105, 688-698.

(29) Kratz, J. M. (2019) Drug discovery for chagas disease: A viewpoint. Acta Trop. 198, 105107105112.

(30) Ramirez, D. M. C., Ogilvie, W. W., and Johnston, L. J. (2010) NBD-cholesterol probes to track cholesterol distribution in model membranes. Biochim. Biophys. Acta - Biomembr. 1798, 558-568.

(31) Kol, M. A., Van Dalen, A., De Kroon, A. I. P. M., and De Kruijff, B. (2003) Translocation of Phospholipids Is Facilitated by a Subset of Membrane-spanning Proteins of the Bacterial Cytoplasmic Membrane. J. Biol. Chem. 278, 24586-24593.

(32) Pohl, J., Ring, A., and Stremmel, W. (2002) Uptake of long-chain fatty acids in HepG2 cells involves caveolae: Analysis of a novel pathway. J. Lipid Res. 43, 1390-1399.

(33) Woodland, J. G., Hunter, R., Smith, P. J., and Egan, T. J. (2017) Shining new light on ancient drugs: preparation and subcellular localisation of novel fluorescent analogues of Cinchona alkaloids in intraerythrocytic Plasmodium falciparum. Org. Biomol. Chem. 15, 589-597. 
(34) Molinspiration Cheminformatics free web services.

(35) Song, W., Wang, W., Wang, Y., Dou, L., Chen, L., and Yan, X. (2015) Characterization of fluorescent NBD-cholesterol efflux in THP-1-derived macrophages. Mol. Med. Rep. 12, 59895996.

(36) Májer, F., Salomon, J. J., Sharma, R., Etzbach, S. V., Najib, M. N. M., Keaveny, R., Long, A., Wang, J., Ehrhardt, C., and Gilmer, J. F. (2012) New fluorescent bile acids: Synthesis, chemical characterization, and disastereoselective uptake by Caco-2 cells of 3-deoxy 3-NBD-amino deoxycholic and ursodeoxycholic acid. Bioorg. Med. Chem. 20, 1767-1778.

(37) Yoshioka, K., Takahashi, H., Homma, T., Saito, M., Oh, K., Nemoto, Y., and Matsuoka, H. (1996) A novel fluorescent derivative of glucose applicable to the assessment of glucose uptake activity of Escherichia coli. Biochim. Biophys. Acta 1289, 5-9.

(38) Tanasova, M., Plutschack, M., Muroski, M. E., Sturla, S. J., Strouse, G. F., and Mcquade, D. T. (2013) Fluorescent THF-Based Fructose Analogue Exhibits Fructose-Dependent Uptake. ChemBioChem 14, 1263-1270.

(39) Jagu, E., Pomel, S., Pethe, S., Cintrat, J. C., Loiseau, P. M., and Labruère, R. (2019) Spermine-NBD as fluorescent probe for studies of the polyamine transport system in Leishmania donovani. Bioorg. Med. Chem. Lett. 29, 1710-1713.

(40) Boiani, L., Aguirre, G., González, M., Cerecetto, H., Chidichimo, A., Cazzulo, J. J., Bertinaria, M., and Guglielmo, S. (2008) Furoxan-, alkylnitrate-derivatives and related compounds as antitrypanosomatid agents: Mechanism of action studies. Bioorg. Med. Chem. 16, 7900-7907.

(41) Penin, P., Sanchez-Moreno, M., and De Diego, J. A. (1998) Proton nuclear magnetic resonance analysis of metabolic end products of the Bolivia strain of Trypanosoma cruzi and three of its clones. Comp. Biochem. Physiol. - A Mol. Integr. Physiol. 120, 571-574.

(42) Zeledon, R. (1960) Comparative Physiological Studies on Four Species of Hemoflagellates in Culture . II. Effect of Carbohydrates and Related Substances and Some Amino Compounds on the Respiration. J. Parasitol. 46, 541-551. 
(43) Cazzulo, J. J. (1994) Intermediate metabolism in Trypanosoma cruzi. J. Bioenerg. Biomembr. $26,157-165$.

(44) Silber, A. M., Colli, W., Ulrich, H., Manso Alves, M. J., and Pereira, C. A. (2005, March) Amino acid metabolic routes in Trypanosoma cruzi: Possible therapeutic targets against Chagas' disease. Curr. Drug Targets - Infect. Disord.

(45) Saugar, J. M., Delgado, J., Hornillos, V., Luque-Ortega, J. R., Amat-Guerri, F., Acuña, A. U., and Rivas, L. (2007) Synthesis and biological evaluation of fluorescent leishmanicidal analogues of hexadecylphosphocholine (Miltefosine) as probes of antiparasite mechanisms. J. Med. Chem. 50, 5994-6003.

(46) Eckstein-Ludwig, U., Webb, R. J., Van Goethem, I. D. A., East, J. M., Lee, A. G., Kimura, M., O'neill, P. M., Bray, P. G., Ward, S. A., Krishna, S., Neill, P. M. O., Bray, P. G., Ward, S. A., and Krishna, S. (2003) Artemisinins target the SERCA of Plasmodium falciparum. Nature 424, 957961.

(47) Woodland, J. G., Hunter, R., Smith, P. J., and Egan, T. J. (2018) Chemical Proteomics and Super-resolution Imaging Reveal That Chloroquine Interacts with Plasmodium falciparum Multidrug Resistance-Associated Protein and Lipids. ACS Chem. Biol. 13, 2939-2948.

(48) Kolb, H. C., and Sharpless, K. B. (2003) The growing impact of click chemistry on drug discovery. Drug Discov. Today 8, 1128-1137.

(49) Agalave, S. G., Maujan, S. R., and Pore, V. S. (2011) Click chemistry: 1,2,3-triazoles as pharmacophores. Chem. - An Asian J. 6, 2696-2718.

(50) Porta, E. O. J., Jäger, S. N., Nocito, I., Lepesheva, G. I., Serra, E. C., Tekwani, B. L., and Labadie, G. R. (2017) Antitrypanosomal and antileishmanial activity of prenyl-1,2,3-triazoles. MedChemComm 8, 1015-1021.

(51) Mancilla, R., Naquira, C., and Lanas, C. (1967) Protein biosynthesis in trypanosomidae. II. The metabolic fate of DL-leucine-1-C14 in Trypamosoma cruzi. Exp. Parasitol. 21, 154-159.

(52) Galvez Rojas, R. L., Ahn, I. Y., Suárez Mantilla, B., Sant'Anna, C., Furusho Pral, E. M., and 
Silber, A. M. (2015) The uptake of GABA in Trypanosoma cruzi. J. Eukaryot. Microbiol. 62, 629636. 